\title{
Designs for Curriculum-Based Telementoring
}

Judi Harris

College of William and Mary

Follow this and additional works at: https://scholarworks.wm.edu/educationbookchapters

Part of the Education Commons

\section{Recommended Citation}

Harris, H. (2011). Designs for curriculum-based telementoring. In Scigliano, D.A. (Ed.). Telementoring in the K-12 classroom: Online communication technologies for learning (pp. 1-14). Hershey, PA: IGI Global.

This Book is brought to you for free and open access by the School of Education at W\&M ScholarWorks. It has been accepted for inclusion in School of Education Book Chapters by an authorized administrator of W\&M ScholarWorks. For more information, please contact scholarworks@wm.edu. 


\title{
Chapter 1 \\ Designs for Curriculum- Based Telementoring
}

\author{
Judi Harris \\ College of William and Mary, USA
}

\begin{abstract}
Telementoring for K-12 students is done primarily outside of school, typically addressing topics that are extrinsic to school curricula. As beneficial as extracurricular telementoring can be, bringing mentors virtually into classrooms to interact with students and teachers over time holds great potential - and considerable challenge-for both. How can telementoring be integrated effectively into content-based curricula taught in face-to-face educational contexts like classrooms? What is key to the success of this type of curriculum-based telementoring? Answers to these questions appear below, illustrated by examples from an informal taxonomy of curriculum-based telementoring projects that were facilitated by the Electronic Emissary (http://Emissary.wm.edu/), the longest-running formal telementoring program for K-12 students and their teachers.
\end{abstract}

\section{INTRODUCTION}

Summarizing the emerging field of social neuroscience, journalist Daniel Goleman (2006, p. 4) asserts that "we are wired to connect." Our brains are designed to be social, and we benefit in measurable ways intellectually, emotionally, and even physically from ongoing, nurturing connections with each other. Given our biological "wiring" and the ever-increasing capabilities and

DOI: 10.4018/978-1-60520-861-6.ch001 availabilities of social networking tools, is it any wonder that our students are drawn so powerfully to multiple forms of networked communication?

Most of the social networking that so many students enjoy (e.g., texting and cell phone use) is done extracurricularly (Lenhart, Ling, Campbell \& Purcell, 2010). Educational technologists are experimenting with "educational networking," seeking to capitalize upon students' attractions to social networking by integrating tool use such as text messaging, microblogging, collaborative document-writing, handheld videoconferencing, 
and wireless phone calls into learning and teaching in K-12 classrooms (Hargadon, 2009). This is challenging work, since more than half of U.S. districts prohibit social networking in school (Deubel, 2009).

Yet one of the oldest and most educationally beneficial forms of social/educational networking - telementoring — has been used formally in elementary, middle-level, and secondary classrooms since at least 1992, long before blogs, wikis, wireless networks and even the multimedia Web found their way into most schools. Indeed, informal e-mentoring among adults emerged in the late 1970's and early 1980's, when universitybased researchers began communicating using networks that had been reserved previously for U.S. government projects (Single \& Single, 2005). Informal online mentoring for K-12 students probably emerged at about the same time, since the first published evidence of email-based educational networking appeared in 1978 (Harris, 2005), and the Free Educational Mail (FrEdMail) network connected schools internationally starting in 1985 ("FrEdWriter and FrEdMail," n.d.).

Telementoring — also called "e-mentoring" and "online mentoring" - is mentoring that happens via educational networking. E-mentoring for K-12 students typically involves sustained exchanges between mentors and protégés, who use electronic mail, discussion forums, texting, and/or videoconferencing to communicate individually or in groups. It differs from using ask-an-expert Web sites (e.g., AllExperts.com) to answer specific questions, because telementoring interactions are much longer and deeper in duration and focus. Curriculum-based telementoring can be an integral part of organized learning for elementary, middle-school, or high school students. It is less common than extracurricular telementoring, however, which typically supports individual students' explorations of career interests, hobbies, and/or personal issues.

When telementoring is designed to function within school-based curricula, rather than extra- curricularly, it can help to bring subject matter alive in ways not possible locally, increasing the depth, breadth, and/or authenticity of students' curriculum-based learning. Communicating regularly with content specialists who share active interest, experience, and expertise in curriculumbased topics can increase students' engagement and connection with standards-based learning, due to the interactive, emergent, and personalized nature of telementoring discussions. Integrating regular e-mentoring into students' classroom activities, however, presents pedagogical challenges for teachers who are unfamiliar with planning for and implementing educational networking within classroom-based instruction (Harris, 2010).

Like social networking, much telementoring happens informally and outside of the school day, with an extracurricular focus. Curriculum-based telementoring - the focus of this chapter-is e-mentoring that is a planned part of students' learning that happens in the classroom. Though this type of mentoring has been used episodically for nearly two decades and with considerable success, its potential is still largely untapped. What is curriculum-based telementoring? How is it similar to and different from other types of educational networking? How can it be structured and used to assist and enhance students' curriculum-related learning? Pragmatic answers to these questions begin with teachers' planning for students' learning, the reasons for which can be understood with a metaphor.

\section{BACKGROUND}

Eh! Je suis leur chef, il fallait bien les suivre. (Ah well! I am their leader, so I must follow them.)

- Alexandre Auguste Ledru-Rollin (Aphids Communications, ๆ 33) 
Effective, meaningful learning is like enjoying a well-prepared, well-presented, and nutritious meal. A good meal can be eaten at home or away, but when it is partaken at a fine restaurant, it is surely the direct result of careful planning and well-coordinated action, born of both culinary and management expertise. Teachers' work in planning and directing effective, meaningful learning opportunities for their students is much like an experienced chef's work on behalf of the patrons at an award-winning restaurant. To be effective, both instruction and fine dining need to be carefully conceptualized, well-planned, wellexecuted, competently managed, and evaluated. Both should meet professional standards without sacrificing creative expression or enjoyment.

This metaphor is included here purposefully. Teachers are chefs - not cooks. Though some would say that these two jobs are the same, in reality they require different experience and expertise, warranting different levels of professional respect. This notion is true even across cultures. For example, in Chinese, the word for "chef" translates to "kitchen master," while the word for "cook" translates to "kitchen worker." In French, "chef" means "chief" or "leader," as the quote from Ledru-Rollin above demonstrates. Chefs and teachers are leaders who do much more than prepare nourishment for the body or the mind. They are designers, managers, human relations specialists, artists, and assessors. Asuccessful chef goes beyond following recipes and combining individual dishes into meals. Similarly, teaching that results in students' effective, meaningful, and transferable learning goes far beyond selecting curriculum standards to address, then following directions in teachers' manuals or curriculum guides.

It is true that both chefs and cooks participate in the preparation of food, and cooking without a chef's involvement meets practical needs in many settings outside of popular restaurants. Similarly, many people without professional preparation in education are able informally to help others learn. Yet it is only the professional teacher who has the requisite knowledge, training, experience, and vision to ensure that students' learning meets curriculum-based standards in the most robust, motivating, and appropriately differentiated ways.

Australian author Michael Russell explains the differences between a chef and a cook with the following excerpts from an article posted at a Web site for aspiring chefs. Metaphorically, this also describes the differences between professional and lay teachers.

Being a cook is not synonymous with being a chef. A chef is a cook, but a cook is not necessarily a chef. Yep, it's true that your mom, your Uncle Pete, and your friend can cook. Mom's pancakes are wonderful, Uncle Pete's barbecue makes you drool in anticipation, and your best friend's spaghetti sauce should be patented but alas, they are still merely cooks, not chefs. Chefs must not only be wonderful cooks; they must also develop menus, stay on top of food costs, manage a staff, plus wear the hats of human resource professional, accountant, teacher, sometimes Mom and Dad, and sometimes friend (or enemy), as well.

Creativity plays a major role in a chef's profession. Not only must the food be impeccably prepared; ... its presentation must be artful and designed to appeal to the most discriminating taste buds. Chefs are also expected to create new, never-before-seen dishes, and for this, a mastery of all types of foodstuffs is required: meats, fish, poultry, herbs, spices; even wines. A cook needs nothing more than a desire to work in the kitchen and deftness with a whisk and spatula, while a chef needs years of training and apprenticeship for certification--almost all of it done on his or her feet. ...A true chef MAKES the recipes, THEN follows them. (Russell, 2007)

Similar to Russell's depictions of chefs, professional teachers often manage both resources and assistants (e.g., teachers' aides, student teachers. and parent volunteers), while balancing many different, often conflicting, types of human relationships (e.g., with students, parents, colleagues, 
and administrators), and the politics inherent in doing so. The most engaging teachers are also often the most creative, yet pragmatic education professionals - the ones who know their students' needs and preferences in ways analogous to how inventive, successful chefs know and serve their clienteles.

For both teachers and chefs, knowledge of new tools, such as educational networking applications, and unfamiliar techniques, such as telementoring, can introduce new possibilities for professional practice. This is especially true for educational technologies and teaching. Yet in the same way that learning to use a food processor or following a recipe to prepare pesto doesn't make someone a chef, mastering the mechanics of using unfamiliar technologies or curriculum-based resources isn't all that is required in integrating those technologies into professional educational practice.

As Russell (2007) asserted, "a true chef makes the recipes, then follows them"- just as a true teacher creates customized plans for learning based upon students' needs and preferences, then implements them in the classroom. In doing so, students' learning needs, framed by content-based instructional standards, guide and shape teachers' work. Indeed, as Ledru-Rollin exclaimed in the quotation that began this section, leaders ("chefs") must actually follow those whom they serve to lead them effectively. Thus, planning a particular learning experience - such as a curriculum-based telementoring project or exchange — must begin, end, and progress based upon students' learning needs and preferences, rather than an intention to use digital technologies in teaching.

\section{Planning Curriculum- Based Telementoring}

During instructional planning, teachers' knowledge is operationalized, in part, through the learning activities that they select, combine, sequence, and redesign (Harris, 2008). Studies of teachers' planning show it to be organized and communicated primarily by learning activities and content goals (John, 2006; Yinger, 1979). Learning activities are "routinized" by teachers over time to simplify the planning and coordinating of classroom activity (Yinger, p. 165), allowing greater flexibility and responsiveness to students in the highly situated and contextualized classroom environment (John, 2006). Unfortunately, comparatively little is known at present about how digital educational technologies are integrated into teachers' planning (Richardson, 2009).

Though planning instruction that is facilitated by use of digital tools and resources can be complex, with each decision influencing aspects of other decisions already made or yet to be determined, planning a particular technologically supported learning event can be described generally as a series of five basic steps:

1. Choosing learning goals.

2. Making practical pedagogical decisions about the nature of the learning experience based upon contextual factors, such as technology access and students' prior experience.

3. Selecting and sequencing appropriate learning activity types that combine to form the learning experience (lesson, project, or unit).

4. Selecting formative and summative assessment strategies that will reveal what and how well students are learning.

5. Selecting tools and resources that will best help students to benefit from the learning experience being planned (Harris \& Hofer, 2009, pp. 23-25).

The order in which these steps are completed varies. Some teachers, for example, prefer to choose assessments before selecting other types of learning activities to include in a plan, while others research resources available (such as laptop carts) before considering activity possibilities. New understanding about the interdependent and complex nature of the content, pedagogical, and technological knowledge that teachers use 
when they integrate educational technologies into curriculum-based learning and teaching - called technological pedagogical content knowledge, or TPACK (Mishra \& Koehler, 2006) - has important implications for instructional planning. Recent TPACK work (e.g., Harris \& Hofer, 2009, 2011) suggests that no matter what the sequence of the "middle three" steps listed above, it is most effective to choose learning goals or objectives (based upon student learning needs) first and the tools that will support their learning last during planning. In this way, the curriculum-focused nature of students' learning is ensured, and pedagogies appropriate to content, context, and needs are selected so that technological choices do not drive instructional plans (Harris \& Hofer, 2009).

\section{Learning Activity Types}

Recent work with the development of teachers' knowledge for technology integration, or TPACK, recommends intentional use of learning activity types during instructional planning (Harris, 2008; Harris \& Hofer, 2009). Activity types function as conceptual planning tools; they comprise methodological shorthand that educators can use to both build and describe plans for standards-based learning experiences. Each activity type captures what is essential about the structure of a particular kind of learning action as it relates to what participants do when engaged in that particular learning-related activity (e.g., "group discussion;" "role play;" "fieldtrip"). Activity types can also serve as efficient communication tools for educators wanting to share their plans for students' learning with each other, as science education lesson study research in Japan has shown (e.g., Linn, Lewis, Tsuchida, \& Songer, 2000). Teachers who plan using activities selected from taxonomies of technologically supported learning activity types report that doing so both assists the development of their technology integration knowledge and broadens the range of learning activities that they include in their plans (Harris \& Hofer, 2011). (The taxonomies are available online via the Activity Types Wiki: http://activitytypes.wmwikis.net/.)

Previous work with telecollaborative, telecooperative, and teleresearch learning activity types (e.g., Harris, 1998) identified telementoring as just one type of learning activity. However, analysis of the structures of the many telementoring projects facilitated by the Electronic Emissary (http://Emissary.wm.edu) - a probono service that has assisted $\mathrm{K}-12$ teachers with planning, implementing, and reflecting upon curriculum-based telementoring projects since 1992 - has revealed that there are at least twelve different types of telementoring learning activities.

Based upon emerging results from research and development with other types of technologically supported learning activities (as explained above), it serves to reason that becoming familiar with (and choosing among) the full range of telementoring activity types, especially during instructional planning, should be helpful to teachers who wish to incorporate telementoring into their students' curriculum-based learning. As Shulman (2002) observed,

Distinctions and taxonomies are tools for thought. We make distinctions for the same reasons we carve a turkey or write our books in chapters - to make the world more manageable. And it's only natural that we further order our distinctions and categories into systems, tables, and taxonomies. Categories and distinctions also can call attention to ideas, principles, or values that hitherto have been ignored. (p. 36)

Previous research and development with the TPACK-based learning activity types described above (e.g., Harris, 2008; Harris \& Hofer, 2009, 2011) has demonstrated that teachers' planning for technologically enhanced learning and teaching is assisted and eased by reviewing all possible activity types, then selecting the ones that best match content-based goals and pedagogies appropriate to students' learning needs and preferences. (This is step 3 in the planning sequence presented above.) The learning activity types are organized into 
simple taxonomies to make their review during planning maximally efficient. The twelve telementoring learning activity types identified to date are presented in an informal taxonomy below, with accompanying examples of e-mentoring projects supported by the Electronic Emissary illustrating each, to help teachers to understand each and all of the telementoring activity options.

\section{Types of Telementoring Activities}

TheElectronic Emissary has sponsored and facilitated approximately 800 telementoring projects since its inception in the fall of 1992. While this is by no means the largest number of telementoring efforts assisted by one organization - the International Telementor Program (http://www. telementor.org/) has supported more than 40,000 in three fewer years, for example - the range and variety of different types of telementoring that the Emissary has assisted is broad. Comparing project summaries prepared by participating teachers, mentors, and Emissary staff (project facilitators) reveals different types of telementoring that can be identified according to the primary communication-based functions and roles that mentors perform, as demonstrated in Table 1.

How to involve mentors in students' curriculum-based project work is often confusing for teachers and students during early attempts at curriculum-based telementoring. The types of activities listed above address that confusion directly by focusing upon mentors' primary communicative functions. In some telementoring projects, mentors perform only one of the twelve functions listed here. In others, they serve in multiple ways, either simultaneously or in sequence, based upon the specifics of the project work in which students are engaged.

\section{Examples of Telementoring Activity Types}

Examples of each of the mentor functions in Table 1 appear below. These are sample project summaries for telementoring efforts sponsored by the Electronic Emissary. They are included here to illustrate the online mentoring functions that distinguish each telementoring learning activity type. They are provided for teachers' review in conjunction with the information in Table 1, to assist with selecting the most appropriate types of telementoring in which teachers will ask their students to engage.

\section{Advise/Coach}

"What kinds of berries were eaten by the Indian tribes in Oregon?" Queries such as this and other questions about the livelihoods of the Indians native to Oregon were explored by the fourth grade students in Elise Tickner's class in Parkdale, Oregon. Dr. Ed Liebow, who works with the Battelle Memorial Institute, guided the students through their explorations of village life, dance and religious ceremonies, Indian legends, and other aspects of native Indian culture. Using this information, the students prepared a video demonstrating their knowledge and featuring their completed projects.

\section{Assist}

Mellie Lewis' 32 3rd grade students participated in a project focused on saltwater and freshwater living environments. Dr. Carl Berman, from California State University, Monterey Bay, first helped them to learn about coral reefs - in particular the damage to the reefs caused by pollution, and the diversity of life that they support. Ms. Lewis' students originally planned to create a saltwater aquarium in their classroom, but decided instead to create a fresh-water aquarium with local species. Students gathered plant and fish specimens 
Designs for Curriculum-Based Telementoring

Table 1. Telementoring activity types

\begin{tabular}{|c|c|}
\hline Mentor's Communication & Description \\
\hline Advise/Coach & $\begin{array}{l}\text { Mentors provide suggestions and formative feedback as students progress with their project-related } \\
\text { work, focusing upon the former. If the focus is upon providing formative feedback, then the type of } \\
\text { telementoring being used is probably Provide Feedback, described below. }\end{array}$ \\
\hline Assist & $\begin{array}{l}\text { Mentors help students to accomplish a particular task by suggesting techniques, resources, directions, } \\
\text { etc. They do not direct, assess, or participate in the project work itself. }\end{array}$ \\
\hline Chat & $\begin{array}{l}\text { Mentors share personal stories, information about themselves and their families, "behind the scenes" } \\
\text { views of their professional work, etc. Typically curriculum- or project-based discussion is not the pri- } \\
\text { mary focus for this type of telementoring. }\end{array}$ \\
\hline Co-Create & Mentors, teachers, and students work jointly on a particular product or experience. \\
\hline Discuss/Debate & Mentors dialogue with students and/or teachers, constructively challenging their assertions and views. \\
\hline Impersonate & $\begin{array}{l}\text { Mentors communicate with students in character, typically as an historically accurate or probable per- } \\
\text { son, or as a protagonist in a book that the students are reading. }\end{array}$ \\
\hline Problem-Solve & $\begin{array}{l}\text { Mentors work alongside students (and often their teachers, too) to solve a complex and longer-term } \\
\text { problem jointly. This differs from the Assist activity type in that here, both the mentor and the student(s) } \\
\text { are working to solve the problem. In an Assist telementoring activity, the mentor is assisting the students } \\
\text { as they engage in the learning activity. }\end{array}$ \\
\hline Provide Feedback & $\begin{array}{l}\text { Mentors send constructive comments and suggestions to students after reviewing successive versions of } \\
\text { their work, usually formatively. }\end{array}$ \\
\hline Question-and-Answer & $\begin{array}{l}\text { Mentors respond to a variety of questions posed by students (individually, in small groups, or as a } \\
\text { teacher-led large group). Typically, mentors and students don't share much about themselves or their } \\
\text { circumstances in this particular type of telementoring. Some mentors dislike this type of telementoring } \\
\text { because their participation can be quite disjointed, time-consuming, and frustrating. }\end{array}$ \\
\hline Share Information & $\begin{array}{l}\text { Mentors recommend (sometimes gathering and sending) specialized resources to assist the students and/ } \\
\text { or teachers with their project work. }\end{array}$ \\
\hline Supervise & $\begin{array}{l}\text { Mentors direct students' project work virtually, functioning as a teacher might direct project work in the } \\
\text { classroom. }\end{array}$ \\
\hline Tutor & $\begin{array}{l}\text { Mentors structure, sequence, and direct individual or small groups of students' learning according to } \\
\text { content-related learning goals (typically remedial or advanced). }\end{array}$ \\
\hline
\end{tabular}

from a local stream, then monitored their activity in the classroom aquarium.

Dr. Berman provided the class with scientific and technical information to assist all stages of their work with the aquarium. He was also available to answer questions posed by the students and to direct them to both online and offline resources related to their interests. He helped the teacher when she requested assistance, providing additional information on marine topics that were of interest to her. At the end of the project, the students returned all of the specimens from the aquarium to the stream.

\section{Chat}

Mentor Susan Gillis Kruman and her high school protégé, Tina, described themselves as "totally engrossed in dancing." Most of their frequent communication consisted of sharing past and present dance experiences, during which they found much in common, despite the difference in their ages. Tina also requested and received help in defining and refining a thesis statement for a senior project on dance. Susan provided both general and specific historical information to help Tina to begin work on the project. 


\section{Co-Create}

In Dallas, Texas, Marilyn Morgan's 25 sixth grade students enlisted the help of their parents to construct a model built to scale with a heat lamp that simulated the sun's effects upon the Earth. The idea for the model and most of the experiments that the students conducted with it originated with cloud physicist Darrel Baumgardner, who works with the National Center for Atmospheric Research. Dr. Baumgardner guided the students and their teacher through the experiments, helping them with data analysis when necessary. Using Darrel's model, Ms. Morgan's students studied the simulated effects of solar fluctuations, clouds, pollution, and vegetation upon global climate.

\section{Discuss/Debate}

The first "Rodney King trial" served as a springboard for discussion and debate among the members of Cindy Hank's senior class in San Angelo, Texas, who worked intensively with anthropologist Steve Maack, who lives and works at a small university in Los Angeles. To help students to understand the charged issues that grew out of this trial and the event that precipitated it, Cindy helped the class to go back in time to learn about and discuss the U.S. Civil Rights Era of the late 1950 's and early 1960's. The particular contributions of Martin Luther King, Jr. to the movement were discussed at length, including his philosophy of nonviolence. In response to one student's question, the class discussed and debated whether the dream referenced in Dr. King's speech had been realized in the time that had elapsed. Current ethnic and economic distributions of the San Angelo, Texas population were related to Civil Rights issues. Present-day minority student experiences with police and racism were compared and contrasted with those that were being faced by African Americans in Los Angeles. The second "Rodney King trial" and its aftermath were discussed as the situation was unfolding. Other related current events - notably the deaths of Marian Anderson and Caesar Chavez-were also explored in the context of civil rights history.

\section{Impersonate}

Medieval scholar Sharon Michalove, writing in the guise of the "Learned Sage", worked online with a group of sixth-grade "Seekers of Knowledge" from Houston, Texas, on a multidisciplinary project that culminated with a costumed recreation of selected aspects of the Middle Ages given as a presentation to their school. The students videotaped their presentation and sent Dr. Michalove a copy to demonstrate what they had learned with her assistance.

\section{Problem-Solve}

Rita Martin and her two classes of eighth graders from Texarkana, Texas explored solutions to the problem of nuclear waste with Dr. Mike Baker, a nuclear engineer at Los Alamos National Laboratory. Their exploration led to many conversations. including presidential candidates' views on nuclear power and weapons, safety precautions for Dr. Baker and others working with nuclear waste, and the effects of nuclear waste on ground water. Thanks to Dr. Baker, Rita and her students also had the opportunity to use antique Geiger counters that Mike donated to the school.

\section{Provide Feedback}

The 12 students in Mary McBeth's practical writing class in San Antonio, Texas corresponded with Maria Raymond, an independent historian / writer with a background in journalism living outside Sacramento, California; David Curcio, a lawyer in Houston, Texas; and Rhonda Tuman, an alumni coordinator for a community college in southern Delaware with experience in editing and reporting. These twelve students worked to improve their writing and editing skills. Each 
professional provided formative feedback to four students' responses to Ms. McBeth's writing activities, while she encouraged the online conversations to delve more deeply into the art and craft of writing.

\section{Question-and-Answer}

Brooks Cima's classes of gifted and talented students in grades 1-5 in Katy, Texas. engaged in independent work about "natural extravaganzas" with Dr. Mike Valentine, a professor of geology and environmental science at the University of Puget Sound in Tacoma, Washington. Brooks' students continued the "active questioning" in which they engaged in the classroom with Dr. Valentine online, addressing topics of interest to them such as earthquakes, volcanoes, tsunamis, and undersea events.

\section{Share Information}

In McAllen, Texas, Janis Lentz's combined fourth and fifth grade students embarked upon a search for their cultural and historical roots. Dr. Jesus F. de la Teja, an Associate Professor of History at Southwest Texas State University, who specializes in the history of Spanish colonial borderlands, served as their mentor. He guided the students toward an accurate historical depiction of their geographic region by providing a variety of multicultural resources and by engaging in one-to-one email conversations, sometimes in the students' first language, Spanish.

\section{Supervise}

Peggy Moates' twenty fifth graders from Talbott Elementary School in Tennessee observed and recorded the behavior of domesticated rats in varying conditions under the virtual supervision of animal ethologist Dr. Beverly Marshall-Goodell. Topics studied included recognizing and rating learned behaviors, recording and reporting data scientifically, and using the scientific method throughout the project. Dr. Marshall-Goodell's questions helped the students to both devise new maze experiments and interpret the authentically "messy data" inevitably collected by novice scientific researchers.

\section{Tutor}

Alan Sills, a teacher in North Caldwell, New Jersey, proposed an interesting independent study for two of his students who were very interested in meteorology and weather forecasting. He linked these students with Captain Brian Newton, an Air Force officer assigned to study ways to improve the forecasting of specific atmospheric parameters. With Brian's generous assistance, the students constructed a website that served as a weather forecasting tutorial for other students interested in topics such as how to read weather maps, how severe storms form and are identified, and the weather patterns identified as El Nino.

Note that in many of these project examples, mentors are assuming multiple roles and serving more than one function, as students' interests and learning needs dictate. These shifts are facilitated by active communication with the students' teacher(s), so that the form(s) of the telementoring can evolve as students, teacher(s), and mentor(s) are engaged in project work.

Additional descriptions of Emissary-facilitated, curriculum-based telementoring projects can be found online at http://Emissary.wm.edu/index. php/pastprojects/listall.html.

\section{Participating in Curriculum- Based Telementoring}

Despite its long-term (though admittedly sporadic) use and its comparatively low technological threshold, telementoring still proves challenging for many teachers to incorporate into their students' curriculum-based learning. Experience directly facilitating telementoring projects via 
the Electronic Emissary suggests that there are three primary aspects of in-school telementoring work that explain why it has not been embraced by more K-12 teachers: communication, contexts, and roles. Each is described below.

\section{Communication}

Due to students' and teachers' crowded school day schedules, most curriculum-based telementoring at present occurs primarily via electronic mail. Email is asynchronous, primarily text-based, and quick, like many popular social networking applications, but it lacks the full spectrum of visual and audible information that we depend upon in faceto-face exchange. Therefore, telementoring by e-mail requires somewhat specialized interaction strategies to create maximal educational benefit for participating students (Harris, Rotenberg, \& O'Bryan, 1997). For example, more frequent and more explicit purpose-setting, progress-reporting, and problem-solving communications are usually necessary online, when compared with face-toface interchange (Kimball \& Eunice, 1999). As Kimball \& Eunice explain, "In a face-to-face setting, facilitators watch body language and facial expression and lots of other signals to develop a sense of what's going on. Participants in virtual learning communities convey this same information in different ways." (p. 5)

\section{Contexts}

The contexts in which most online mentors work are quite different from K-12 teaching/learning environments. Of particular note are differences in Internet accessibility, and the expectations that such contrasts can create. Most mentors have easy and frequent access to multiple networking tools throughout their workday, and are accustomed to having brief, text-based or videoconferenced conversations with colleagues with quick turnaround times. In most school districts, due to online safety concerns, K-12 students and teachers have much less frequent and much more inconvenient access to educational networking. Whereas a mentor might expect a reply to an e-mail message within 24 hours, many K-12 students are able to respond to e-mail during class only a few times each week. Mostmentors working outside the K-12 classroom don't realize how different their working contexts are from what teachers and students experience in their schools. So that potential misunderstandings are minimized, teachers must communicate directly with mentors to help them to adjust their expectations of the amount, frequency, and types of communication that can fit the realities of both working environments (Harris \& Figg, 2000).

\section{Roles}

When teachers decide to provide curriculumbased telementoring for their students, their role expands to include work as a project facilitator, directing the progress of the project, reading all messages that are exchanged between the mentor and the student, and assessing students' learning as it occurs. Since this can be overwhelming for some teachers, the Electronic Emissary provides facilitation by staffmembers who are experienced teachers familiar with incorporating telementoring into curriculum-based learning. Unfortunately, not all telementoring services are able to provide facilitation.

Facilitation of telecollaborative work is both emergent and participant-centered. As Kimball \& Eunice (1999) explain,

Facilitation is paying attention to what is happening in your group, as distinct from what you wanted or expected would happen...y you want to detect where members are now and work with that energy to move in the direction [they] need to go. (p. 5)

What must teachers do to successfully facilitate a telementoring project for their students? Typically, they: 
1. Set up, test, and resolve networking technical issues (accounts, filters, etc.).

2. Communicate privately with the mentor, so that the two can be comfortable both personally and professionally while collaborating on the telementoring project.

3. Set realistic project goals and expectations that are in line with curricular standards and sequences.

4. Describe their students and the nature of the learning that they will be doing during the telementoring project to the mentor.

5. Determine and provide answers to procedural questions, both in the classroom and within the online communication that is occurring.

6. Adjust goals and expectations according to project developments over time.

7. Keep communication flowing throughout the project period.

8. Identify, address and resolve miscommunications as promptly as possible.

9. Structure and guide different kinds of online activities, based upon students' learning needs and preferences.

10. Evaluate individual student and group contributions to learning/teaching, ensuring that curriculum standards are met. (Harris \& Figg, 2000)

\section{Benefits}

Given that these responsibilities are added to the heavy load that teachers already bear, perhaps it is no wonder why more educators haven't chosen to incorporate telementoring - or even educational networking in general - into their professional repertoires. But for those who do, and those who will do so in the future, there is substantial benefit to be gained by students, teachers, and even mentors.

Members of well-functioning telementoring teams engage in in-depth, dynamic exchange. Project evaluation results provided by Electronic Emissary team members have emphasized the importance of the relationships that have devel- oped among the participants. Subject matter can "come alive" for students who interact over time with someone for whom curriculum content is part of everyday life, and a passionate interest. Many participating teachers develop close, apprenticelike relationships with online mentors, requesting and receiving assistance with content-related concepts, resources, and even learning activity design. Mentors typically delight in opportunities to revisit and explore new aspects of their disciplinary specializations as they respond to students' and teachers' questions and requests for assistance. For example, a professor at Yale University who was serving as a mentor with the Electronic Emissary wrote:

Thank you for the opportunity to participate once again in the Electronic Emissary Program. It was a pleasure working with the students, and I found it both helpful and encouraging to communicate with my future students while they were still in their formative years. Some of their questions showed a curiosity and sophistication which unfortunately seems to vanish by the time they make it to college! I regularly showed their questions to my colleagues in different departments here (whose help I often received in formulating a reply, and from whom I steal all the credit $<$ wink $>$ ) and they were frequently impressed that their own research interests were mirrored in the students' questions.

The often personal, sometimes challenging, yet in-depth communication co-constructed by people who often have not met face-to-face speaks to the potential power and value of curriculum-based telementoring. As Goleman's (2006) summary of new understandings in neuroscience emphasizes, the importance of deep connections among and between people, especially as children and teens are maturing, cannot be overestimated. Yet paradoxically, at a time when social networking tools seem to provide endless and ever-increasing opportunities for us to connect with each other, the nature of their most popular uses may be 
minimizing students' opportunities to experience the most beneficial types of connections: those that are longer-term, intellectually stimulating, and compassionate.

\section{FUTURE DIRECTIONS/CONCLUSION}

Goleman is among a growing number of writers who see social networking tools as working against forming the kinds of interpersonal connections that are crucial to healthy intellectual, emotional, and social development and functioning. He writes, for example:

Then there are the unknowns in the ways humans around the world are connecting - and disconnecting - as technology offers more varieties of nominal communication in actual isolation. These trends all signal the slow vanishing of opportunities for people to connect. This inexorable technocreep is so insidious that no one has yet calculated its social and emotional costs.... To the extent that technology absorbs people in a virtual reality, it deadens them to those who are actually nearby. The resulting social autism adds to the ongoing list of unintended human consequences of the continuing invasion of technology into our daily lives. (Goleman, 2006, pp.7-8)

To characterize "technology" in this way is not uncommon, unfortunately. Upon closer examination, however, it becomes clear that it is the predominant uses of technology-in this case, social networking tools - that can disrupt and inhibit the kinds of connections that our brains crave and our minds and hearts need. As educators and as citizens, we can choose to use social networking tools in ways that are beneficial and educationally sound. Educational networking can capitalize upon the irresistibly social nature of the tools without sacrificing the potential quality and depth of interpersonal connections. Telementoring is one powerful example of how networked technologies can be used in mutually and maximally beneficial ways.

As other chapters in this book demonstrate, mentoring has long been understood and experienced to be a powerful form of personal and professional learning. Telementoring can be similarly so, though most online mentoring advocates recommend its use only when face-to-face mentoring is impossible or impractical (Single \& Single, 2005). Why is curriculum-based telementoring not more commonly used in K-12 classrooms? Though definitive answers to this question have not yet been determined, it is probable that teachers' and students' predominant experiences with the Web as an information portal, and networked communication tools used mostly or exclusively for social purposes, have concealed these tools' powerful educational networking potential. Given models for different types of curriculum-based telementoring, as described in this chapter, along with examples of telementoring efforts and the practical pedagogical advice that appear in this book, it is my hope that more teachers will be inspired and motivated to design and facilitate curriculum-based telementoring for and with their students.

\section{REFERENCES}

Aphids Communications. (n.d.). Quotations about politics/government. The Quotations Archive. Retrieved August 11, 2010, from http:/www. aphids.com/cgi-bin/quotes.pl?act=ShowListing sForSub\&Subject=S30

Deubel, P. (2009, September 16). Social networking in schools: Incentives for participation. Collaboration 2.0 Newsletter. Retrieved August 10,2010, from http://thejournal.com/articles/2009/09/16/ social-networking-in-schools-incentives-forparticipation.aspx 
FrEdWriter and FrEdMail. (n.d.). In Global SchoolNet's Global Schoolhouse. Retrieved August 11, 2010, from http://www.globalschoolnet. org/gsnabout/history/fredhistory.cfm

Goleman, D. (2006). Social intelligence: The revolutionarynewscience of human relationships. New York: Bantam Dell.

Hargadon, S. (2009). Educational networking: The importantrole Web 2.0 will play in education. Calgary, Alberta: Elluminate Canada. Retrieved August 10, 2010, from http://www.scribd.com/ doc/22279609/Hargadon-Educational-SocialNetworking

Harris, J. (1998). Virtual architecture: Designing and directing curriculum-based telecomputing. Eugene, OR: International Society for Technology in Education, University of Oregon.

Harris, J. (2005). Curriculum-based telecomputing: What was old could be new again. In Kearsley, G.(Ed.), Onlinelearning: Personal reflections on the transformation of education (pp. 128-143). Englewood Cliffs, NJ: Educational Technology Publications.

Harris, J. (2010). Facilitated telementoring for K-12 students and teachers. In Berg, G. A. (Ed.), Cases on online tutoring, mentoring, and educational services (pp. 1-11). Hershey, PA: IGI Global. doi:10.4018/978-1-60566-876-5.ch001

Harris, J., \& Hofer, M. (2009). "Grounded" technology integration: Planning with curriculumbased learning activity types. Learning and Leading with Technology, 37(2), 22-25.

Harris, J., Rotenberg, L., \& O’Bryan, E. (1997). Results from the Electronic Emissary Project: Telementoring lessons and examples. Denton, TX: University of North Texas, Texas Center for Educational Technology. Retrieved August 9, 2010, from http://www.tcet.unt.edu/pubs/em/em01.pdf
Harris, J.B.(2008). TPACK in inservice education: Assisting experienced teachers' planned improvisations. In AACTE Committee on Innovation \& Technology (Eds.). Handbook of technological pedagogical content knowledge for educators (pp. 251-271). New York: Routledge.

Harris, J. B., \& Figg, C. (2000). Participating from the sidelines, online: Facilitating telementoring projects. ACM Journal of Computer Documentation, 24(4), 227-236. Retrieved August 9, 2010, from http://portal.acm.org/citation. cfm?id=353927.353934

Harris, J. B., \& Hofer, M. J. (in press). Technological pedagogical content knowledge (TPACK) in action: A descriptive study of secondary teachers' curriculum-based, technology-related instructional planning. Journal of Research on Technology in Education, 43(3).

John, P. D. (2006). Lesson planning and the student teacher: Re-thinking the dominant model. Journal of Curriculum Studies, 38(4), 483-498. doi:10.1080/00220270500363620

Kimball, L., \& Eunice, A. (1999, November). Zen and the art of facilitating virtual learning communities. Paper presented at the ThinkQuest Teachers' Summit, Los Angeles, CA.

Lenhart, A., Ling, R., Campbell, S., \& Purcell, K. (2010). Teens and mobile phones (Research report, April 20, 2010). Washington, DC: Pew Research Center, Pew Internet \& American Life Project. Retrieved August 10, 2010, from http://pewinternet.org/Reports/2010/Teens-andMobile-Phones.aspx

Linn, M., Lewis, C., Tsuchida, I., \& Songer, N. (2000). Beyond fourth-grade science: Why do U.S. and Japanese students diverge? Educational Researcher, 29(3), 4-14. 
Mishra, P., \& Koehler, M. J. (2006). Technological pedagogical content knowledge: A framework for integrating technology in teacher knowledge. Teachers College Record, 108(6), 1017-1054. doi:10.1111/j.1467-9620.2006.00684.x

Richardson, K. W. (2009). Looking at/looking through: Teachers planning for curriculum-based learning with technology (Doctoral dissertation). Available from ProQuest Dissertations and Theses database. (AAT 3371354)

Russell, M. (2007). The difference between a chef and a cook. Retrieved December 17, 2007, from http://chef-guide.com/a/321859/The+Difference + Between + A + Chef + And + A + Cook.html
Shulman, L. S. (2002). Making differences: A table of learning. Change, 34(6), 36-44. doi:10.1080/00091380209605567

Single, P. B., \& Single, R. M. (2005). E-mentoring for social equity: Review of research to inform program development. Mentoring \& Tutoring, 13(2), 301-320. doi:10.1080/13611260500107481

Yinger, R. (1979). Routines in teacher planning. Theory into Practice, 18(3), 163-169. doi:10.1080/00405847909542827 